\title{
Heat and Mass Transfer in Fry Drying of Wood
}

\author{
D. Grenier, ${ }^{1,2}$ P. Bohuon, ${ }^{1,3}$ J.-M. Méot, ${ }^{1}$ D. Lecomte, ${ }^{4}$ and H. Baillères ${ }^{1}$ \\ ${ }^{1}$ CIRAD, Montpellier, France \\ ${ }^{2} C T B A$, Bordeaux, France \\ ${ }^{3}$ ENSIA, Montpellier, France \\ ${ }^{4}$ ENSTIMAC, Campus Jarlard, Albi, France
}

\begin{abstract}
This article describes the coupled heat and mass (water, oil) transport phenomena in parallelepiped samples of beech (Fagus sylvatica) fried in peanut oil between 120 and $180^{\circ} \mathrm{C}$. The aim was to evaluate the suitability of simultaneous fry drying and oil impregnation as an alternative wood treatment process. Water loss and oil impregnation were continuously assessed during the process. Temperature and pressure were measured at the center of the sample. The water in the peripheral layers of the wood vaporizes at atmospheric pressure. The water at the center of the wood vaporizes at overpressures of the order of $2.8 \times 10^{5} \mathrm{~Pa}$. High fluxes of water were recorded of about $0.006 \mathrm{~kg} /\left(\mathrm{m}^{2} \mathrm{~s}\right)$. The impregnated oil can amount to $20 \%$ of the mass of the removed water.
\end{abstract}

Keywords Drying; Frying; Heat transfer; Mass transfer; Oil; Wood

\section{INTRODUCTION}

For the last two decades, the frying process has been of interest to food scientists and the food industry. It essentially fulfils two functions: dehydration and oil impregnation. A technological re-evaluation has also resulted in the development of new applications. The most recent have been drying and texturizing of fatty foodstuffs (avocado, cocoa, etc.) to improve their pressability, ${ }^{[1,2]}$ drying and roasting of coffee, ${ }^{[3]}$ drying and compaction of vegetable products, drying of sewage sludge,${ }^{[4]}$ and drying of wood and its formulation. ${ }^{[5,6]}$

The heat transfer drives water transport within the material. During frying, heat is transported by natural convection to the vicinity of the material/oil interface and by conduction within the material. ${ }^{[6]}$ Coupled heat and mass transfer develops and two distinct regions appear within the material: a dried peripheral region and a water-rich core. These regions are separated by an interface that moves from the periphery to the center as the transfer

Correspondence: Philippe Bohuon, CIRAD, TA 10/15, 73 rue J.F. Breton, 34398 Montpellier cedex 5, France; E-mail: philippe. bohuon@cirad.fr progresses. ${ }^{[7,8]}$ In the simplest case of the slab exposed to hot oil from both sides, the one half of the slab can be represented as a double-layer structure formed of two distinct parallel regions, each with homogeneous properties. The total thermal resistance $\left(R_{e q}^{(t)}\right)$ to heat transfer between the oil and the water-saturated central region can be described as a sum of a convective resistance $1 /\left(h^{(t)} A^{(t)}\right)$ and a conductive resistance $e^{(t)} /\left(k^{(t)} A^{(t)}\right)$; i.e., $R_{e q}^{(t)}=1 /\left(h^{(t)} A^{(t)}\right)+e^{(t)} /\left(k^{(t)} A^{(t)}\right)$, where $h^{(t)}$ is the convective heat transfer coefficient, $e^{(t)}$ is the thickness of the dried region, $k^{(t)}$ is the apparent thermal conductivity of the dried region, and $A^{(t)}$ is the exchange area. The heat transfer coefficient $h^{(t)}$ is directly linked to the release of vapor bubbles. The evaporative flux creates intense agitation in the oil close to the product. This coefficient immediately starts to fall, from its initial value of 1500 to 200 $\mathrm{W} /\left(\mathrm{m}^{2} \mathrm{~K}\right)$ at the end of frying. ${ }^{[9]}$ The convection generated by the bubbles doubles the $h^{(t)}$ coefficient with no release of bubbles as reported by Costa et al. ${ }^{[10]}$ These authors show that the convective heat transfer coefficient increases in proportion to the evaporative flux, but the external transfers are far less limiting than conduction within the product.

Conductive heat transfer heats the product to the water saturation temperature $\left(T_{\text {sat }} \approx 100^{\circ} \mathrm{C}\right.$ at $\left.101.35 \mathrm{kPa}\right)$, usually over a short period of time. Although the material center is maintained at $T_{\text {sat }}$, the water vapor can create local overpressure, depending on the nature and structure of the material. Overpressures of $40 \mathrm{kPa}$ have been reported in food gels. ${ }^{[11]}$ The pressure gradient generates a vapor flux from the center to the periphery of the material. Movements of liquid water have also been reported.$^{[11,12]}$ Most of the thermal conduction resistance occurs in the dry zone that develops in the course of frying $\left(e^{(t)}\right.$ increases). The conduction resistance increases when dry zone expands and its water content falls. In many cases, this resistance limits transfer processes. At high moisture content, the saturation temperature is the same as the boiling temperature of the water. The more the product dries out, the more its temperature increases 
(hygroscopic zone). The equilibrium relationship between boiling temperature and water content is specific for each product. ${ }^{[13,14]}$ From a thermal point of view, most of the energy is used to vaporize the water. Because of the pressure gradient, little external oil infiltrates from the outside to inside the material during the frying of food materials. Yet most of the oil penetrates at the end of frying and during the cooling phase. ${ }^{[7,8,11,15]}$

The heat and mass transfer mechanisms have essentially been described in relation to frying of foodstuffs, even though for a long time a high-temperature processing in a liquid medium such as oil has been used to treat wood. ${ }^{[16]}$ In this case, the oil temperature ranges from 140 to $220^{\circ} \mathrm{C}$, depending on the species. Though the drying rate increases with temperature, at higher temperatures a risk of splitting is, however, greater. ${ }^{[17,18]}$

To bridge the gap in fundamental research of fry-drying of wood, the objective of the present study was set as to characterize the heat and mass transfers in parallelepiped samples of beech (Fagus sylvatica) during immersion in peanut oil at temperatures ranging from 120 to $180^{\circ} \mathrm{C}$.

\section{MATERIALS AND METHODS}

\section{Wood}

The wood was 60-year-old beech (Fagus sylvatica). It was cut into parallelepipeds with dimensions of $0.16 \times 0.05 \times 0.03 \mathrm{~m}$ following the longitudinal $(\mathrm{Lo})$, radial (Ra), and tangential (Ta) directions, respectively. Measurements had an uncertainty of $\pm 1 \times 10^{-3} \mathrm{~m}$. Twelve samples from the same batch were used. The oven-dry density of the wood was $630 \pm 30 \mathrm{~kg} / \mathrm{m}^{3}$. The samples were initially kept under vacuum for four hours, then wetted by immersing into water for $48 \mathrm{~h}$ at $20^{\circ} \mathrm{C}$ at a pressure of $\sim 5 \times 10^{5} \mathrm{~Pa}$. Their average initial water content was $W_{s}^{(0)}=1.2 \pm 0.1 \mathrm{~kg} / \mathrm{kg} \mathrm{db}$. Each sample was then placed in a metal clamp (Fig. 1), which applied a pressure on a $3 \mathrm{~mm}$ thick silicone membrane located at each end of the wood sample. The membranes limited mass transfer in the direction of the fibers (longitudinally) at both ends of the sample, allowing two-dimensional mass transfer (in the tangential and radial directions) to be hypothesized.

\section{Frying Conditions and Equipment}

An insulated fryer with dimensions of $0.30 \times$ $0.15 \times 0.13 \mathrm{~m}$ (model KPB 50, Kenwood, Paris, France) was filled with $4 \mathrm{~kg}$ of peanut oil. The oil was heated by a $1.8-\mathrm{kW}$ electric element positioned $0.03 \mathrm{~m}$ above the base of the fryer. This arrangement provided a cold zone below the element. Oil temperature, $T_{\infty}$, was controlled by a digital PID controller, and regulation was based on temperature readings from three thermocouples positioned around the sample. Data acquisition and temperature control were performed by software (Labview version 5.1,

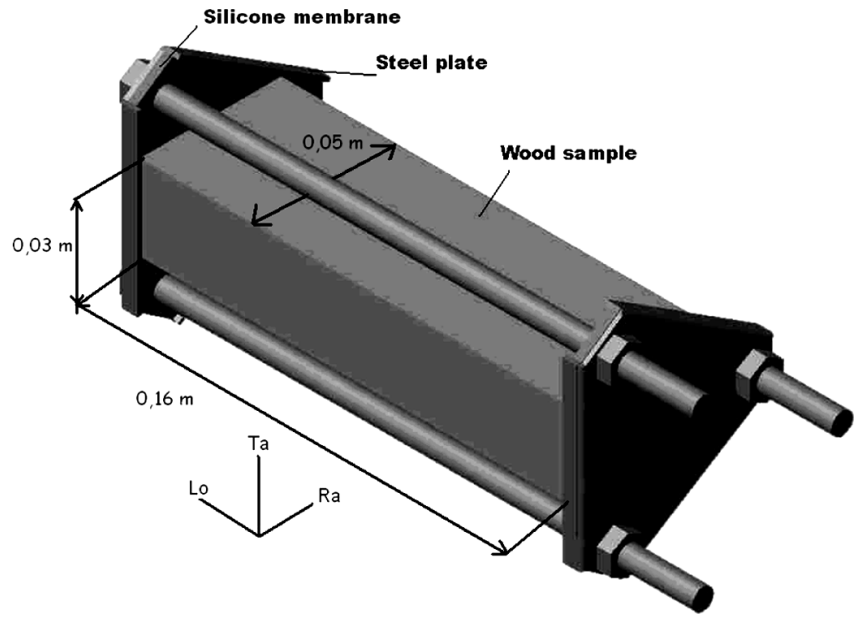

FIG. 1. Apparatus sealing both ends of the parallelepiped of wood (Lo: longitudinal direction, in the direction of the wood fibers; Ta: tangential direction, perpendicular to the wood fibers and wood rays, Ra: radial direction, perpendicular to the wood fibers and following the wood rays). Only 2D transfers in directions $\mathrm{Ta}$ and $\mathrm{Ra}$ are possible.

National Instrument, Austin, USA) adapted to our requirements. Maximum temperature variations around the sample were in the $T_{\infty}-1{ }^{\circ} \mathrm{C}$ to $T_{\infty}+3^{\circ} \mathrm{C}$ range. Samples were fried at three different temperatures $\left(T_{\infty}=120,150\right.$, and $\left.180^{\circ} \mathrm{C}\right)$ for $3 \mathrm{~h}$ at atmospheric pressure. The initial mass of each sample was $0.305 \mathrm{~kg}$. The weight measurement strategy developed to measure simultaneous water vapor loss and oil impregnation is presented in Fig. 2. The balance 1 (Sartorius, France; capacity $31 \mathrm{~kg}$, precision $\pm 1 \times 10^{-3} \mathrm{~kg}$ ) measured the total weight of the frying equipment (fryer + oil + buoyancy of the sample), while the balance 2 (Sartorius, France; capacity $3.1 \mathrm{~kg}$, precision $\pm 1 \times 10^{-3} \mathrm{~kg}$ ) measured the weight of the wood immersed in the oil bath (sample-buoyancy). Weights were recorded at 5-min intervals.

\section{Measurement of Temperature and Pressure in the Wood}

Temperature and pressure at the centre of the sample were measured simultaneously by a probe consisting of a 1-mm-diameter thermocouple ( $\mathrm{K}$ thermocouple, TCSA, France) and a miniature 3-mm-diameter pressure sensor (XCEL-100, 0-700 kPa, KULITE). The thermocouple and pressure sensor were embedded in epoxy resin in a PEEK tube with an 8-mm external diameter and a 4-mm internal diameter (Fig. 3). The outside of the tube was threaded to fit tightly into the wood. A thin layer of silicone oil $(<2 \mathrm{~mm})$ covered with a latex membrane separated the pressure sensor from the moisture contained in the wood. The thread at the end of the probe was covered with a Teflon film and then screwed into a hole previously tapped in the sample. Temperature and pressure measurements had an uncertainty of $\pm 2^{\circ} \mathrm{C}$ and $\pm 10 \mathrm{kPa}$, respectively. 


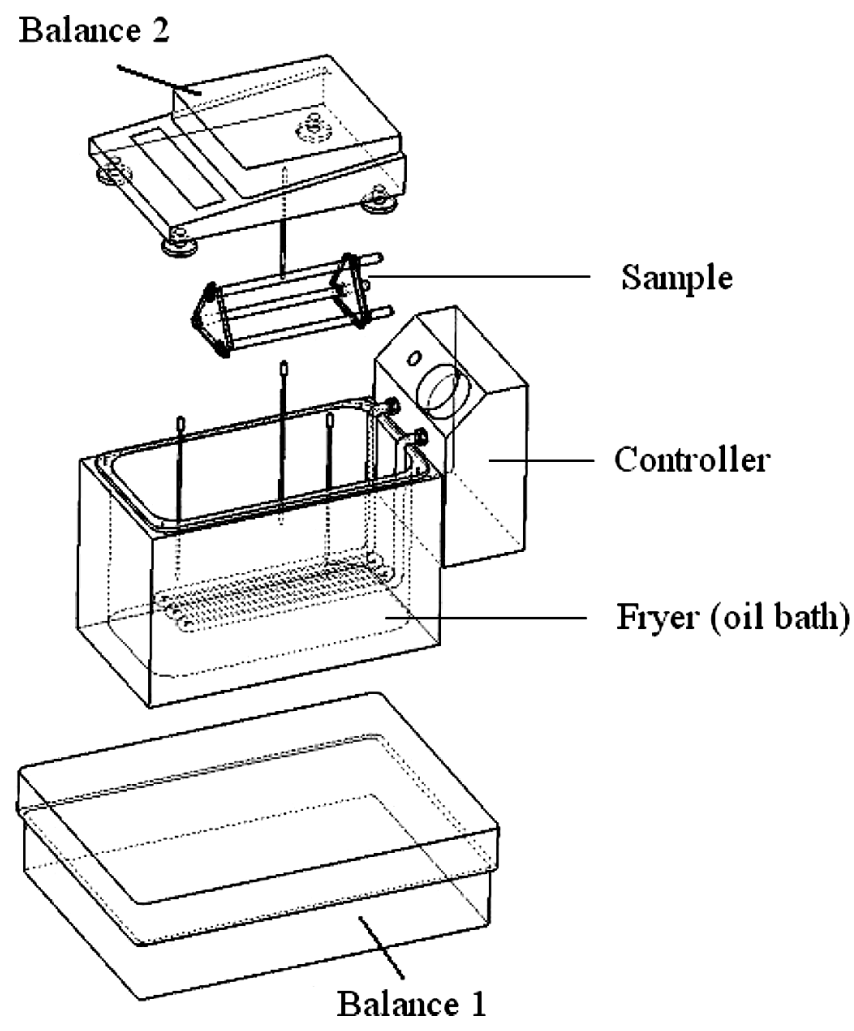

FIG. 2. Experimental apparatus to measure the water and oil contents simultaneously by differential weighing (after Vitrac ${ }^{[1]}$ ). Balance 1 weighs the entire system (fryer + oil) while Balance 2 weighs the wood and the clamp holding it.

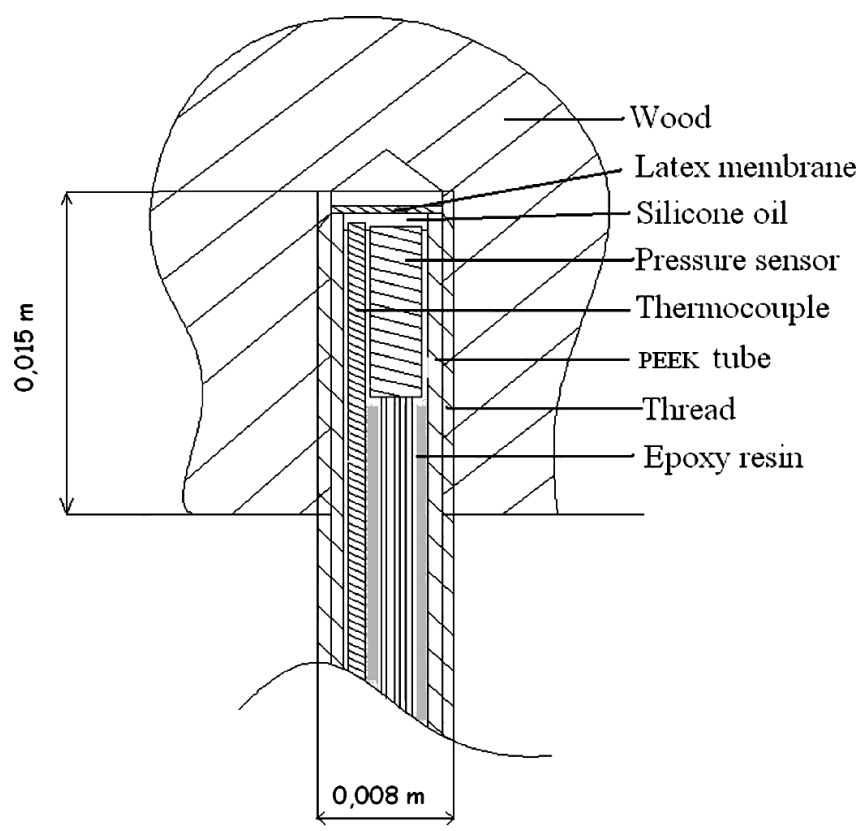

FIG. 3. Device for simultaneous measurement of pressure and temperature at the center of a wood sample.

\section{Measurement of Area and Volume}

The dimensions of the sample were measured with a Vernier caliper at 5-min intervals and compared with a control sample. The total surface area, noted $A^{(t)}$, corresponds to the sum of the surface areas of all faces of the sample. Area and volume measurements had an uncertainty of $\pm 1 \times 10^{-3} \mathrm{~m}^{2}$ and $\pm 2 \times 10^{-3} \mathrm{~m}^{3}$, respectively.

\section{Measurement of Water Content $\left(W_{s}^{(t)}\right)$}

Water content at time $t$, noted $W_{s}^{(t)}$, is expressed relative to the initial mass of the dry and oil-free matter $(\mathrm{kg} / \mathrm{kg})$ :

$$
W_{s}^{(t)}=W_{s}^{(0)}-\frac{\left(m_{2}^{(0)}-m_{2}^{(t)}\right)+\left(m_{1}^{(0)}-m_{1}^{(t)}\right)}{m_{\text {wood }}^{(0)}\left(1-W^{(0)}\right)}
$$

where $W_{s}^{(0)}$ and $W^{(0)}$ are the initial water content expressed respectively in dry basis and wet basis, and $m_{1}^{(t)}$ and $m_{2}^{(t)}$ are the masses $(\mathrm{kg})$ at time $t$ indicated by Balances 1 and 2, respectively. The initial mass of the wood $(\mathrm{kg})$ is $m_{\text {wood }}^{(0)}$.

\section{Measurement of Oil Content $\left(O_{s}^{(t)}\right)$}

Oil content, noted $O_{s}^{(t)}$ is expressed relative to the initial mass of dry oil-free matter $(\mathrm{kg} / \mathrm{kg})$

$$
O_{S}^{(t)}=\frac{\left(m_{1}^{(0)}-m_{1}^{(t)}\right)-\rho_{\text {oil }}\left(V_{\text {wood }}^{(0)}-V_{\text {wood }}^{(t)}\right)}{m_{\text {wood }}^{(0)}\left(1-W^{(0)}\right)}
$$

where $V_{\text {wood }}^{(t)}$ is the volume of the wood at time $t$, and $\rho_{\text {oil }}$ is the density of the oil at the temperature under consideration.

\section{Continuous Estimation of Water Flux}

The plot of water content $\left(W_{s}^{(t)}\right)$ as a function of time was smoothed using cubic smoothing splines $\left(\right.$ Matlab $^{\circledR}$ Version 5.2, The Mathworks Inc., Natick, MA). Water vapor flux as a function of time, noted $q_{w}^{(t)}$, was calculated from the smoothed curve by direct derivation $\left(d W_{s}^{(t)} / d t\right)$ and expressed in $\mathrm{kg} /\left(\mathrm{m}^{2} \mathrm{~s}\right)$.

$$
q_{w}^{(t)}=-\frac{m_{w o o d}^{(0)}\left(1-W^{(0)}\right)}{A^{(t)}} \frac{d W_{s}^{(t)}}{\mathrm{d} t}
$$

\section{Approximate Quasi-Steady-State Analysis for a Flat Geometry}

The stabilization of the temperature close to $T_{\text {sat }}$, determined by the pressure, indicates the presence of a vaporization front, which moves from the periphery toward the center of the wood as frying progresses. Two levels of heat and water transfer coupling need to be taken into account in such a case: (1) at the vaporization front - $a$ coupling between the heat transfer and the vaporization flux; (2) at the wood/oil interface-the coupling between 
the flux of water vapor bubbles (boiling) and the convective heat transfer coefficient. Further, a one-dimensional slab of thickness $2 l$ is assumed to undergo phase transformation due to heating from both sides. During frying, the temperature at the center rapidly rises to the saturation vapor temperature, $T_{\text {sat }}$, and is then maintained to the end of frying. The sensible heat of the dry zone is negligible compared to the latent heat of water vaporization. Notable temperature distribution will occur within the dry zone due to its low thermal conductivity and, ignoring the sensible heat effect, this distribution will be linear. The position of the liquid vapor front $\left(e^{(t)}\right)$ as a function of time can be described by a heat balance at the interface, based on the convective and conductive thermal resistances:

$$
\rho_{b} W^{(0)} \lambda \frac{d e^{(t)}}{d t}=\frac{\left(T_{\infty}-T_{\text {sat }}\right)}{\left(1 / h^{(t)}+e^{(t)} / k^{(t)}\right)}
$$

Integrating Eq. (4) gives Eq. (5): ${ }^{[19]}$

$$
\frac{2 e^{(t)}}{l}=-\frac{1}{B i}+\sqrt{\frac{1}{B i^{2}}+2 \text { Ste Fo }}
$$

where $B i$ is the Biot number defined as $B i=h^{(t)} l / 2 k^{(t)}$, Ste is the Stephan number defined as Ste $=c_{p}\left(T_{\infty}-T_{s a t}\right) /$ $\left(W^{(0)} \lambda\right)$, and $F o$ is the Fourier number defined as $F o=\left(k^{(t)} / \rho_{b} c_{p}\right)(2 / l)^{2} t$.

The water content of the dry area is assumed to be the critical water content $W_{s}^{s a t} \approx 0.03 \mathrm{~kg} \cdot \mathrm{kg}^{-1}$ (i.e., the water content at which the temperature is much higher than the saturation vapor temperature $T_{\text {sat }} \sim 103^{\circ} \mathrm{C}$ ). The water content at the center of the wood remains constant $\left(W^{(0)}\right)$ throughout the frying. The value of $e^{(t)}$ can, therefore, be calculated from a global mass balance on $W_{s}^{(t)}$ between the dry zone (at $W_{s}^{\text {sat }}$ ) and the wet core (at $W_{s}^{(0)}$ ).

$$
e^{(t)} \frac{(L+l)}{L l}=\frac{W_{s}^{(0)}-W_{s}^{(t)}}{W_{s}^{(0)}-W_{s}^{s a t}}
$$

The convective heat transfer coefficient is adjusted so that the experimental $\left(W_{s}^{(t)}\right)$ data correspond to the calculated ones. The Biot number characterizing heat transfer between oil and the vaporization front is then defined as $h^{(t)} e^{(t)} / k^{(t)}$

\section{RESULTS AND DISCUSSION}

\section{Typical Drying Curve}

To study drying kinetics and pressure/temperature evolution, 10 replicated experiments were conducted for determining the drying curves under the same experimental conditions and 10 for pressure-temperature measurements. Pressure variation between 1.5 and $5 \times 10^{5} \mathrm{~Pa}$ was observed depending on the quality of the obstruction.

The following data interpretation is illustrated by a single experiment representative for pressure and temperature

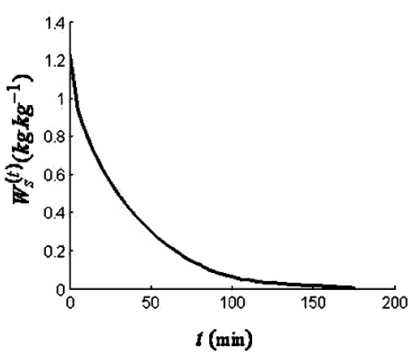

(a)

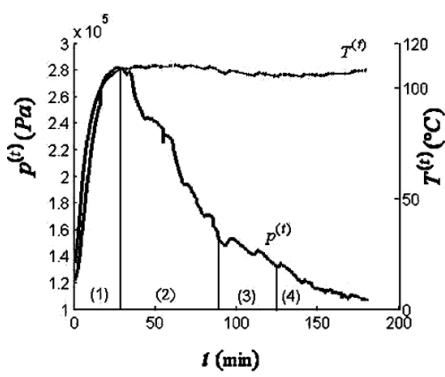

(c)

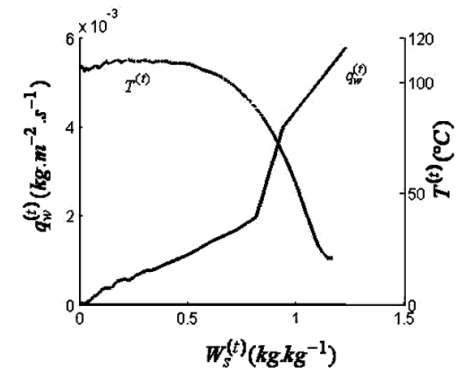

(b)

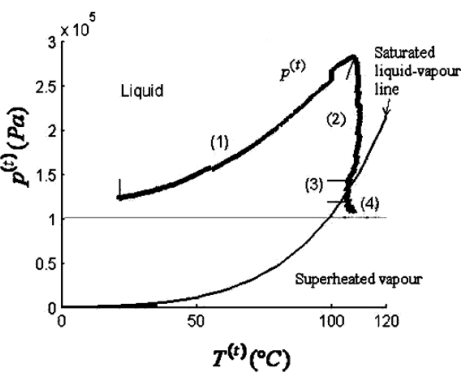

(d)

FIG. 4. Evolution as a function of time of: (a) the water content of the wood sample $W_{s}$; (b) temperature at the center of the wood sample and the water flux; (c) temperature and pressure at the center of the wood; (d) thermodynamic trajectory of the center of the wood sample. Frying performed in an oil bath at $180^{\circ} \mathrm{C}$. (1) Stage 1: Increase in the temperature at the center of the wood. (2) Stage 2: Stabilization of the temperature at $T_{\text {sat }}$, and decrease of pressure. (3) Stage 3: Vaporization at the center of the wood sample. (4) Stage 4: Increase in the temperature after disappearance of the liquid water. 
(measured at the same time at the center of the wood) with the corresponding drying curve.

Figure 4a presents the drying kinetics for wood fried at $180^{\circ} \mathrm{C}$. The measured initial water vapor flux (Fig. 4b) is approximately $6.5 \times 10^{-3} \mathrm{~kg} /\left(\mathrm{m}^{2} \mathrm{~s}\right)$. Fry-drying at $180^{\circ} \mathrm{C}$ is an extremely intense and rapid form of drying, as half of the initial mass of water is removed in $25 \mathrm{~min}$, whereas the total drying time approaches $180 \mathrm{~min}$. The water flux continually decreases with drying time without a distinct initial period of drying at constant flux. After the first few minutes of drying, a major flux of water as vapor bubbles occurs accompanied by intense boiling. In the first $10 \mathrm{~min}$, the water flux decreases from $6.5 \times 10^{-3}$ to $2 \times 10^{-3} \mathrm{~kg} /\left(\mathrm{m}^{2} \mathrm{~s}\right)$. During these first $10 \mathrm{~min}$, the sample shrinks by roughly $5 \%$. Then, the water flux reduces further once a critical water content of about $0.9 \mathrm{~kg} / \mathrm{kg}$ is reached and falls by a half between water content of 1.0 and $0.8 \mathrm{~kg} / \mathrm{kg}$.

Figure $4 \mathrm{c}$ presents the evolution of the pressure and temperature over the fry-drying time at the geometric center of the wood sample. The small initial overpressure recorded is an artefact resulting from the overpressure of the air caused by screwing the pressure probe into the wood. There is a notable increase in the pressure (Stage 1) to nearly $280 \mathrm{kPa}$. It should be noted that this level of pressure was recorded in beech only when both ends of the wood were sealed before frying. In our case, the complete sealing of the ends of the parallelepiped enabled us to simulate the behavior of an infinitely long beam. The pressure then fell while the temperature remained constant (Stage 2). It stabilized at the saturation vapor pressure $\left(p_{\text {sat }}\right)$ corresponding to the temperature at the front. Thereafter, when both temperature and pressure correspond to the saturated liquidvapor line, the vaporization began at the sample center (Stage 3). So, it took $83 \mathrm{~min}$ for the vaporization front to reach the center of the wood, traveling $0.012 \mathrm{~m}$ at an average speed of $3 \times 10^{-6} \mathrm{~m} / \mathrm{s}$. The simultaneous presence of liquid water and water vapor at the center of the wood lasted about $34 \mathrm{~min}$, so we can evaluate the width of the vaporization front as approximately $0.006 \mathrm{~m}$. Only the vapor and the water associated with the center of the wood are then present during the Stage 4. Figure 4d shows this diagrammatically $(p, T)$. More particularly, this graph can be used to characterize the thermodynamic trajectory recorded at the center of the wood. This thermodynamic trajectory represents the "identity card" of the fry-drying process. ${ }^{[20]}$ Stages (1), (2), and (3), to the left of the saturated liquid-vapor line, are in the (liquid) saturation domain. Stage (4), to the right of the curve, corresponds to the superheated vapor domain. The high pressure at the centre of the wood is reached in the area above the liquid-vapor curve. In Stage (2), saturated liquid water is present in the center of the wood despite the fact that the temperature is above $103^{\circ} \mathrm{C}$. The pressure at the center of the wood is determined by the pressure at the vaporization front, where the phase transformation occurs. Permeability in the transverse direction of the wood (perpendicular to the fibers) is about $10^{-15} \mathrm{~m}^{2}$. ${ }^{[21]}$ The very low permeability limits evacuation of the water vapor and therefore creates high levels of pressure. The identity card noted during fry-drying is similar to the identity drying card described by Perré for microwave drying of wood. ${ }^{[20]}$

\section{Oil Temperature Effect}

Figure 5a shows the drying curves during frying in an oil bath at 120,150 , and $180^{\circ} \mathrm{C}$. The curves (each curve is based on the means from three experiments) for highand low-temperature drying have the same overall shape.

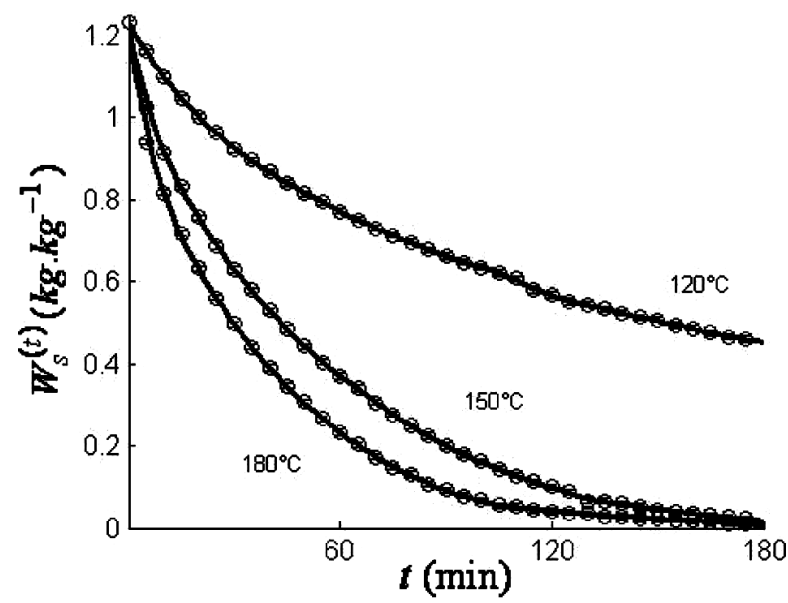

(a)

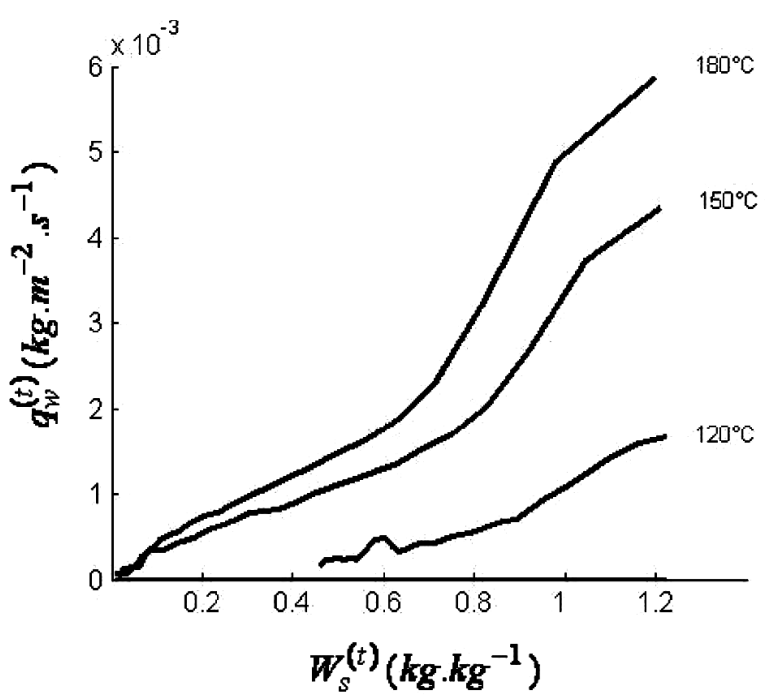

(b)

FIG. 5. (a) Evolution of the water content of the wood $W_{s}$ as a function of time. (b) Water flux $q_{w}^{(t)}$ as a function of the water content $W_{s}$. Frying performed in an oil bath at 120,150 , and $180^{\circ} \mathrm{C}$. 
The time required to remove $50 \%$ of the initial amount of water reduces from $100 \mathrm{~min}$ to $25 \mathrm{~min}$ when the oil bath temperature is increased from 120 to $180^{\circ} \mathrm{C}$. The measured initial water flux (Figure 5a) is approximately $6.5 \times 10^{-3} \mathrm{~kg} /\left(\mathrm{m}^{2} \mathrm{~s}\right)$ at $180^{\circ} \mathrm{C}, 4 \times 10^{-3} \mathrm{~kg} /\left(\mathrm{m}^{2} \mathrm{~s}\right)$ at $150^{\circ} \mathrm{C}$, and $1.5 \times 10^{-3} \mathrm{~kg} /\left(\mathrm{m}^{2} \mathrm{~s}\right)$ at $120^{\circ} \mathrm{C}$. At the inception of drying, the water fluxes are more or less proportional to the difference between $T_{\infty}$ and $T_{\text {sat }}$. The higher the oil bath temperature, the faster the drying. There is again no drying phase with a constant water flux, whatever the value of $T_{\infty}$ (Fig. 5b), which indicates on internal transfers as the limiting ones. After a high water flux at the beginning of drying, a rapid drop in the water flux is noted, when the water content falls below $0.9 \mathrm{~kg} / \mathrm{kg}$ at $120^{\circ} \mathrm{C}, 1.0 \mathrm{~kg} / \mathrm{kg}$ at $150^{\circ} \mathrm{C}$, and $1.0 \mathrm{~kg} / \mathrm{kg}$ at $180^{\circ} \mathrm{C}$. Thereafter, the lines gradually level off. Once the saturation vapor temperature is reached, the temperature difference $\left(T_{\infty}-T_{\text {sat }}\right)$ remains constant (Fig. 4c). The reduction in the water flux can probably be attributed to the increase in conduction resistance as a result of the progressively increasing depth of the dry zone.

\section{Oil Penetration}

Figure 6 shows the evolution of the oil content in the wood sample as a function of its water content (each curve is based on the means from three experiments). The oil content is low at the start of frying, on the order of $0.02 \mathrm{~kg} / \mathrm{kg}$. While the water content is between 0.7 and $1.2 \mathrm{~kg} / \mathrm{kg}$, the oil is present only at the surface of the wood and no considerable penetration occurs. The oil starts to penetrate

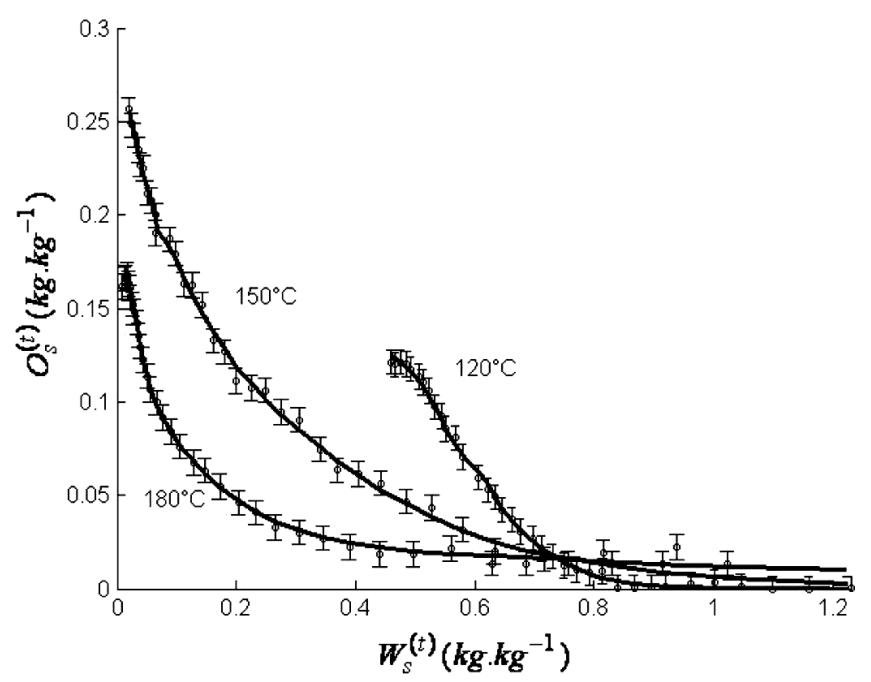

FIG. 6. Evolution of the oil content of the wood $O_{s}^{(t)}$ as a function of its water content $W_{s}^{(t)}$. Frying performed in an oil bath at 120,150, and $180^{\circ} \mathrm{C}$. Vertical bars indicate standard deviation. into the wood when the water content falls below a critical value $(0.4$ to $0.7 \mathrm{~kg} / \mathrm{kg})$. The higher the oil temperature, the lower the critical value. At $120^{\circ} \mathrm{C}$, the oil starts to penetrate into the wood at $0.7 \mathrm{~kg} / \mathrm{kg}$, while at $180^{\circ} \mathrm{C}$ the penetration starts at $0.4 \mathrm{~kg} / \mathrm{kg}$. Beyond this critical value, oil penetration increases progressively to an asymptotic value. For the same amount of water removed during frying, the lower the oil temperature, the higher the oil impregnation. Once $0.8 \mathrm{~kg}$ of water has been removed from an initial $2.2 \mathrm{~kg}$ of wet wood (i.e., $1.0 \mathrm{~kg}$ of dry matter), $0.12 \mathrm{~kg}$ of oil has penetrated into the wood at $120^{\circ} \mathrm{C}, 0.05 \mathrm{~kg}$ at $150^{\circ} \mathrm{C}$, and $0.025 \mathrm{~kg}$ at $180^{\circ} \mathrm{C}$. The wood is simultaneously dried and impregnated with oil, and the rate increases as the drying progresses. The impregnated oil can amount to $20 \%$ of the mass of the removed water. Throughout the impregnation, the wood is at an overpressure relative to the pressure of the oil bath. The direction of the oil flux is therefore opposite to the total pressure gradient, so spontaneous impregnation can only occur if the wood is able to absorb the oil. This hypothesis is partially confirmed by the existence of a saturation threshold beyond which the oil does not penetrate into the wood. However, this threshold depends on oil temperature; the higher the oil temperature, the higher the internal pressure and the lower the threshold water content. Oil impregnation can be caused by two mechanisms: it can result from spontaneous absorption or it can be vapor driven. The first mechanism does not require interaction with the vapor transfers. It develops spontaneously, with the threshold water content effects, if the wood has stronger affinity to oil than to water. For the second mechanism to operate, the capillary forces between the oil and the wood must be overcome by a positive pressure gradient in the wood as the water vapor and the oil move in opposite directions. The above description is similar to the vapor drive described by the BuckleyLeverett model. ${ }^{[2]}$ Observation of the samples during frying showed that the vapor has preferential paths. Most of the vapor was evacuated along the vascular rays. This

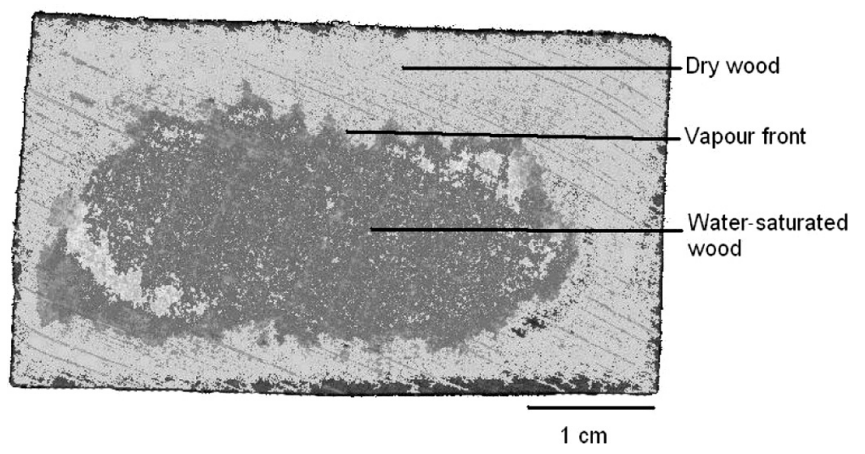

FIG. 7. Photographic image of the vaporization front after $60 \mathrm{~min}$ of frying at $180^{\circ} \mathrm{C}$. 
suggests a mechanism of spontaneous impregnation that does not require cross fluxes. In this case, the penetration of the oil would essentially be due to increasing absorption by the fibers as they dry out and to capillarity penetration.

\section{Identification of Limiting Transfers}

Figure 7 shows a photograph of a middle cross section of a wood sample fried at $180^{\circ} \mathrm{C}$ and removed from the oil bath after one hour. The central water-saturated zone is clearly distinguishable from the peripheral dry zone. This

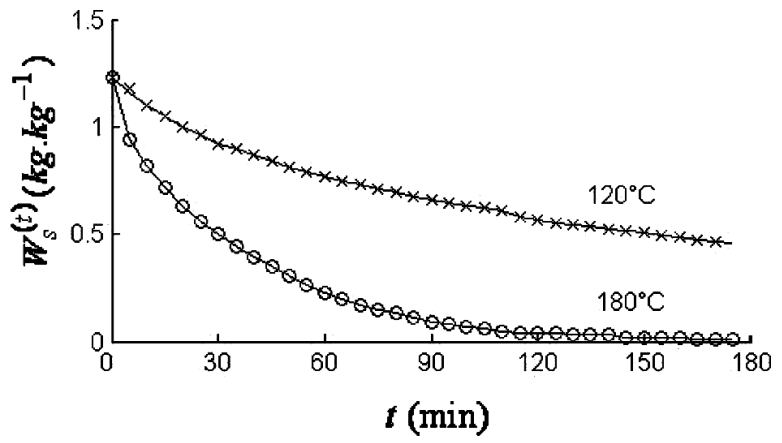

(a)

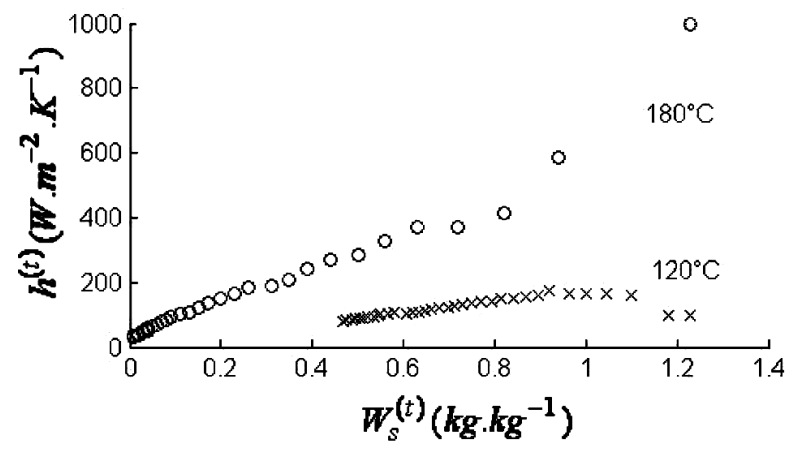

(b)

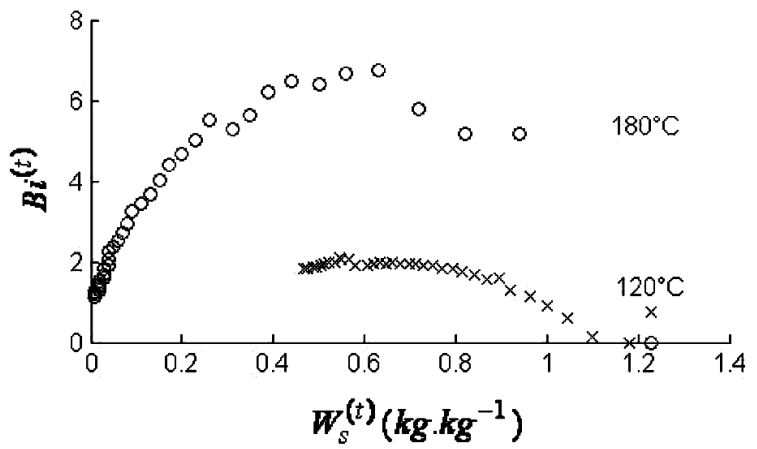

(c)

FIG. 8. (a) Comparison of the water content of the wood $W_{s}^{(t)}$ as a function of time, showing experimental data $(\circ, \times)$ and model adjusted to the data (-). (b) Convective heat transfer coefficient $h^{(t)}$ values obtained using the adjusted $W_{s}^{(t)}$ data. (c) Biot number $\mathrm{Bi}$ as a function of $W_{s}^{(t)}$. Frying performed in an oil bath at 120 and $180^{\circ} \mathrm{C}$. strengthens the hypothesis of the advance of a vaporization front, with most of the conduction resistance in the peripheral "dry" zone.

Figure $8 \mathrm{~b}$ presents the convective heat transfer coefficient as a function of the wood's water content for frying at 120 and $180^{\circ} \mathrm{C}$. The convective heat transfer coefficient ranged from 90 to $150 \mathrm{~W} /\left(\mathrm{m}^{2} \mathrm{~K}\right)$ for an oil temperature of $120^{\circ} \mathrm{C}$, and from 40 to $600 \mathrm{~W} /\left(\mathrm{m}^{2} \mathrm{~K}\right)$ for $180^{\circ} \mathrm{C}$. These values are consistent with the literature data. ${ }^{[23-25]}$ The reported ranges of $h^{(t)}$ values are $200-780 \mathrm{~W} /\left(\mathrm{m}^{2} \mathrm{~K}\right)$ $\left(160-190^{\circ} \mathrm{C}\right),{ }^{[23]} \quad 40-2000 \mathrm{~W} /\left(\mathrm{m}^{2} \mathrm{~K}\right) \quad\left(140-160^{\circ} \mathrm{C}\right),{ }^{[24]}$ and $70-335 \mathrm{~W} /\left(\mathrm{m}^{2} \mathrm{~K}\right) \quad\left(150-190^{\circ} \mathrm{C}\right) .{ }^{[25]}$ The Biot number is greater than 1 after the first few minutes of frying. The convective heat transfer between the wood and the hot oil is far less limiting than the internal heat transfer. Thermal conductivity was here set at the constant value of $0.2 \mathrm{~W} /(\mathrm{mK})$ when determining $h^{(t)}$ although the oil penetrates into the wood during frying. This is justified by the fact that the thermal conductivity of the oil is of the same order. At $120^{\circ} \mathrm{C}$, the $h^{(t)}$ value is lower. However it is still far higher than for traditional air drying $\left(5<h^{(t)}<30 \mathrm{~W} /\right.$ $\left.\left(\mathrm{m}^{2} \mathrm{~K}\right)\right) .{ }^{[18]}$ In the latter case, the external heat transfer can be the limiting factor during the very first minutes, with a Biot number less than 1.0 for a water content above $0.9 \mathrm{~kg} / \mathrm{kg}$.

\section{CONCLUSIONS}

The fry-drying of wood is a type of boil-drying. Frydrying is a rapid drying process and can be used to dry in a few hours wood that would take several days to dry by traditional air drying. The convective transfer coefficient is between 40 and $600 \mathrm{~W} /\left(\mathrm{m}^{2} \mathrm{~K}\right)$ and increases as the water vapor flux increases. The heat transfer within the wood very rapidly becomes the limiting factor, compared to the convective heat transfer. There are high water content gradients in the wood, with a peripheral dry zone and a much wetter core. The transfer phenomena can appropriately be represented by a receding front model. The depth of the receded vaporization front is small, less than $10 \%$ of the total sample thickness. Higher pressure at the vaporization front creates the pressure gradient between the vaporization front and the periphery of the wood, which drives to the wood surface. The pressure in the wet zone, i.e., from the vaporization front to the center of the wood sample, appears to be uniform; the values of pressure at the center of the wood sample and at the vaporization front are probably virtually identical. This overpressure front would move from the periphery to the center of the wood sample until all the liquid water has transferred into vapor. The drying would then be completed. During frying, the oil penetrates into the material and the impregnated oil can amount to as much as $20 \%$ of the quantity of removed water. Globally, penetration takes place in the radial direction and intensifies as the vapor flux falls. Water loss and oil impregnation are coupled, but their dynamics are distinct. 


\section{NOMENCLATURE}

$A^{(t)} \quad$ Wood area at time $t\left(\mathrm{~m}^{2}\right)$

$c_{p} \quad$ Specific heat $\left(\mathrm{J} \cdot \mathrm{kg}^{-1} \cdot \mathrm{K}^{-1}\right)$

$e^{(t)} \quad$ Thickness of the dry area at time $t(\mathrm{~m})$

$h^{(t)} \quad$ Convective heat coefficient at time $t$

$\left(\mathrm{W} \cdot \mathrm{m}^{-2} \cdot \mathrm{K}^{-1}\right)$

$k^{(t)} \quad$ Thermal conductivity $\left(\mathrm{W} \cdot \mathrm{m}^{-1} \cdot \mathrm{K}^{-1}\right)$

(Value 0.2$)^{\dagger}$

$L \quad$ Wood width (m)

$l \quad$ Wood thickness $(\mathrm{m})$

$m_{i}^{(t)} \quad$ Mass indicated by balance $i$ at time $t(\mathrm{~kg})$

$m_{\text {wood }}^{(t)} \quad$ Wood mass at time $t(\mathrm{~kg})$

$O_{s}^{(t)} \quad$ Oil content $(\mathrm{db})$ at time $t\left(\mathrm{~kg}_{\mathrm{oil}} \cdot \mathrm{kg}_{\text {drywood }}^{-1}\right)$

PEEK PolyEtherEtherKetone

$p^{(t)} \quad$ Wood pressure $\left(\mathrm{p}_{\mathrm{a}}\right)$

$q_{w}^{(t)} \quad$ Vapour flux at time $t\left(\mathrm{~kg} \cdot \mathrm{m}^{-2} \cdot \mathrm{s}^{-1}\right)$

$T^{(t)} \quad$ Wood temperature $\left({ }^{\circ} \mathrm{C}\right)$

$T_{\infty} \quad$ Oil temperature $\left({ }^{\circ} \mathrm{C}\right)$

$T_{\text {sat }} \quad$ Boiling temperature $\left({ }^{\circ} \mathrm{C}\right)$ (Value 103)

$t \quad$ Time (min)

$V_{\text {wood }}^{(t)} \quad$ Wood volume at time $t^{*}\left(\mathrm{~m}^{3}\right)$

wood

Critical water content $(\mathrm{db})\left(\mathrm{kg}_{\text {water }} \cdot \mathrm{kg}_{\text {drywood }}^{-1}\right)$ (Value 0.03)

$W^{(t)} \quad$ Wood water content (wb) at time $t$ $\left(\mathrm{kg}_{\text {water }} \cdot \mathrm{kg}_{\text {total }}^{-1}\right)$

$W_{s}^{(t)} \quad$ Wood water content $(\mathrm{db})$ at time $t$ $\left(\mathrm{kg}_{\text {water }} \cdot \mathrm{kg}_{\text {drywood }}^{-1}\right)$

\section{Greek Symbols}

$\lambda \quad$ Water vapor latent heat $\left(\mathrm{kJ} \cdot \mathrm{kg}^{-1}\right)$ (Value 2257)

$\rho_{b} \quad$ Wood density $\left(\mathrm{kg} \cdot \mathrm{m}^{-3}\right)$ (Value 630)

$\rho_{i} \quad$ Density of element i $\left(\mathrm{kg} . \mathrm{m}^{-3}\right)$

\section{ACKNOWLEDGMENT}

We thank Garth Evans for the English translation.

\section{REFERENCES}

1. Hounhouigan, J.; Rouzière, A.; Noël, J.M.; Bricas, N.; Marouzé, C.; Raoult-Wack, A.L. Relance de la Filière de Production D'huile de Coco par la Technique de Séchage Friture. In Récents Progrès En Génie Des Procédés, Groupe Français Du Génie Des Procédés. Technique Et Documentation; Raoult-Wack, A.L., Graille, J., Trystram, G., Eds.; Lavoisier: Cachan, 1993; 121-130.

2. Lisse, I.; Raoult-Wack, A.-L. Drying of meat materials (lean and fat) by deep-fat frying in animal fat. Sciences des Aliments 1998, 18 (4), 423-435.

3. Grewal, P.S. Rapid Oil Roasting of Coffee Beans; UK Patent: GB 2 286108 A, 1996.

4. Peregrina, C.; Lecomte, D.; Arlabosse, P. Fry-drying of sewage sludge: An alternative for the disposal of recycled food oils. International Conference of Engineering and Food, Montpellier, 2004; 154-160.

${ }^{\dagger}$ From Perré. ${ }^{[26]}$

*Times begin at start of frying.
5. Rapp, A.O.; Sailer, M. Oil heat treatment of wood in Germany-State of the art. Proceedings of the Special Seminar of European Cooperation in the Field of Scientific and Technical Research, Reinbek, Antibes, France, February 9, 2001; 47-64.

6. Farkas, B.E.; Hubbard, L.J. Analysis of convective heat transfer during immersion frying. Drying Technology 2000, 18 (6), 1269-1285.

7. Farkas, B.E.; Singh, R.P.; Rumsey, T.R. Modeling heat and mass transfer in immersion frying. II, Model solution and verification. Journal of Food Engineering 1996, 29 (2), 227-248.

8. Moreira, R.G.; Castell Perez, M.E.; Barrufet, M.A. Deep-Fat Frying Fundamentals and Applications; Aspen Publishers: New York, 1999.

9. Singh, R.P. Heat and mass transfer in foods during deep-fat frying. Food Technology 1995, 49 (4), 134-137.

10. Costa, R.M.; Oliveira, F.A.R.; Delanay, O.; Gekas, V. Analysis of the heat transfer coefficient during potato frying. Journal of Food Engineering 1999, 39 (3), 293-299.

11. Vitrac, O. Caractérisation Expérimentale et Modélisation de L'opération de Friture; Ph.D. thesis, ENSIA, 2000.

12. Vitrac, O.; Bohuon, P. Internal coupled heat and mass transfer during deep-frying of materials with high water contents: Application to apple chips fried at atmospheric pressure. Proceedings of the International Conference of Engineering and Food, Montpellier, France, 2004; 177-183.

13. Bassal, A.; Vasseur, J.; Loncin, M. Sorptions isotherms of food materials above $100^{\circ} \mathrm{C}$. Lebensmittel Wissenschaft und Technologie 1993, 26, 505-511.

14. Courtois, F.; Trystram, G.; Lemaire, R.; Raoult-Wack, A.L. Modelling of deep fat frying of banana using a compartmental approach and Boiling's theory. Proceedings of the 11th International Drying Symposium (IDS '98), Greece, August 19-22, 1998; 1452-1459.

15. Baik, O.D.; Mittal, G.S. Heat and moisture transfer and shrinkage simulation of deep-fat tofu frying. Food Research International 2005, 38 (2), 183-191.

16. Kollman, F.; Wilfred, A., Eds. Principles of Wood Science and Technology; Springer-Verlag: New York, 1968; 324-325.

17. Arnesen, J.H. Rea Specification Wood Poles Stubs and Anchor Logs; Bulletin of the United States Department of Agriculture Rural Electrification Administration, 1728F(700), Washington, 1993; 2-47.

18. Perré, P. Le Séchage du Bois. In Le Bois Matériau D’ingénierie; Jodin, P., Ed.; Arbolor: Nancy, France, 1994; 58-61.

19. Farid, M. A unified approach to the heat and mass transfer in melting, solidification frying and different drying processes. Chemical Engineering Science 2001, 56, 5419-5427.

20. Perré, P. Drying with internal vaporisation: Introducing the concept of identity drying card. Drying Technology 1995, 13 (5-7), 1077-1097.

21. Siau, J.F. Permeability. In Transport Processes in Wood; SpringerVerlag: New York, 1984; 73-103.

22. Cunha, M.C.C.; Santos, M.M.; Bonet, J.E. Buckley-Leverett mathematical and numerical models describing vertical equilibrium process in porous media. International Journal of Engineering Science 2004, 42 (11-12), 1289-1303.

23. Budzaki, S.; Seruga, B. Determination of convective heat transfer coefficient during frying of potato dough. Journal of Food Engineering 2005, 66 (3), 307-314.

24. Vitrac, O.; Trystram, G.; Raoult-Wack, A.-L. Continuous measurement of convective heat flux during deep-frying: Validation and application to inverse modeling. Journal of Food Engineering 2003, 60 (2), 111-124.

25. Sahin, S.; Sastry, S.K.; Bayindirli, L. The determination of convective heat transfer coefficient during frying. Journal of Food Engineering 1999, 39 (3), 307-311.

26. Perré, P. Advances in transport phenomena during convective drying with superheated steam and moist air. Journal of Heat and Mass Transfer 1993, 36 (11), 2725-2746. 